\title{
A Study of Vehicle Structural Layouts in Post-WWII Aircraft
}

\author{
Mark D. Sensmeier* \\ Embry-Riddle Aeronautical University, Prescott, Arizona, 86301 \\ Jamshid A. Samareh ${ }^{\dagger}$ \\ NASA Langley Research Center, Hampton, Virginia, 23681
}

\begin{abstract}
In this paper, results of a study of structural layouts of post-WWII aircraft are presented. This study was undertaken to provide the background information necessary to determine typical layouts, design practices, and industry trends in aircraft structural design. Design decisions are often predicated not on performance-related criteria, but rather on such factors as manufacturability, maintenance access, and of course cost. For this reason, a thorough understanding of current "best practices" in the industry is required as an input for the design optimization process. To determine these best practices and industry trends, a large number of aircraft structural "cutaway" illustrations were analyzed for five different aircraft categories (commercial transport jets, business jets, combat jet aircraft, singleengine propeller aircraft, and twin-engine propeller aircraft). Several aspects of wing design and fuselage design characteristics are presented here for the commercial transport and combat aircraft categories. A great deal of commonality was observed for transport structure designs over a range of eras and manufacturers. A much higher degree of variability in structural designs was observed for the combat aircraft, though some discernable trends were observed as well.
\end{abstract}

\section{Nomenclature}

Frames $\quad=$ Circumferential fuselage structures which help maintain fuselage shape and prevent skin buckling

Longerons $=$ Lengthwise fuselage structures which carry bending loads

Ribs $\quad=$ Chordwise wing structures which maintain wing shape, carry shear, and prevent skin buckling

Spars $\quad=$ Spanwise wing structures which provide primary wing resistance to aerodynamic bending loads

\section{Introduction}

$\mathrm{I}_{\mathrm{t}}^{\mathrm{N}}$ $\mathrm{N}$ recent years, a substantial body of research has been focused on development of multidisciplinary optimization techniques and their application to the aero-structural design of aerospace vehicles. While much progress has been made in the ability to rapidly and automatically generate computational fluid grids to assess different external shapes based on parametric designs, the structural aspects of the design optimization problem have not enjoyed the same attention. Often, the structural layout is fixed and only the sizing of the load-carrying components is considered in the selection of design variables. In the few instances where structural layout is allowed to vary, the model used to analyze and assess candidate designs is usually fairly simplistic, which may suffice for conceptual design but is less than optimal for preliminary or detail design. Aircraft manufacturers have very accurate ("down to the last rivet") structural models of existing vehicles, but these models take literally months to generate and are not suitable for rapid consideration of candidate designs. Thus, there is a need for a methodology to create structural models of reasonably high accuracy while incorporating the ability to generate these models automatically for arbitrary external vehicle shapes. This capability will bring enhanced fidelity into the early design process.

\footnotetext{
* Assistant Professor, Aerospace Engineering Dept., 3700 Willow Creek Rd., Prescott, AZ 86301, (928)777-3847, mark.sensmeier@erau.edu, Senior Member AIAA.

${ }^{\dagger}$ Senior Research Scientist, Multidisciplinary Optimization Branch, MS 159, Hampton, VA 23681-2199, (757)8645776, jamshid.a.samareh@nasa.gov, Associate Fellow, AIAA.
} 
As a first step towards developing this capability, it is necessary to construct an abstraction of the aircraft structural elements and their layout that can be utilized to build these models. This abstraction must be realistic enough to allow for easy mapping of existing design configuration, flexible enough to handle unusual or creative designs, and expandable enough to incorporate modern concepts such as smart material actuators, etc. In addition, the abstraction should be conducive to implementation in an automated sense so that models can be created quickly for a given structural layout regardless of changes in the external shape or size.

This paper deals not with the structural abstraction itself, though, but rather with the results of a study of existing aircraft structural layouts. This study was undertaken to provide the background information necessary to determine typical layouts, design practices, and industry trends in aircraft structural design. While there is certainly room for substantial innovation in the development of future vehicles, design decisions are often predicated not on aerostructural performance-related criteria, but rather on criteria related to such factors as manufacturability, maintenance access, and of course cost (including not just material or fabrication costs, but costs of developing new tooling, etc.). For this reason, a thorough understanding of current "best practices" in the industry is required and should be incorporated into the optimization process. It would be inefficient to optimize in regions of design space that are not realistic or even feasible. Though the goal of optimization in general is to obtain the "best" design which may in fact be very different from existing designs, neglecting a century of "lessons learned" could yield designs which are optimum on paper but stand no chance of being built due to cost or political considerations.

\section{Procedure}

Determining industry's best practices and structural design rules and guidelines could be a very simple exercise. Aircraft manufacturers have already assimilated this information and published it in the form of design manuals used extensively by their designers. However, the information in these manuals is extremely competition-sensitive and for obvious reasons is not published in the open literature. Fortunately the nature of the creator can be inferred reasonably well from the characteristics of the creation. A large body of illustrations of aircraft internal arrangements, known as "cutaways", exists in the open literature ${ }^{1-6}$. A typical cutaway drawing is shown in Fig. 1. Though these are not dimensioned manufacturing blueprints, they are meticulously drawn by a handful of devoted artists who either had access to manufacturing details or deduced them by observing the visible evidence of the hidden skeleton (e.g. rivet lines, etc.). The goal of this study was not to obtain exact aircraft topologies, but rather to identify common design patterns for particular vehicle classes. Thus, the accuracy of most of these drawings, while not 100 percent, is certainly high enough for this purpose. The use of standard aircraft " 3 -view" drawings (see Fig. 2 for example) can help in obtaining accurate estimates for the location and size of certain design elements.

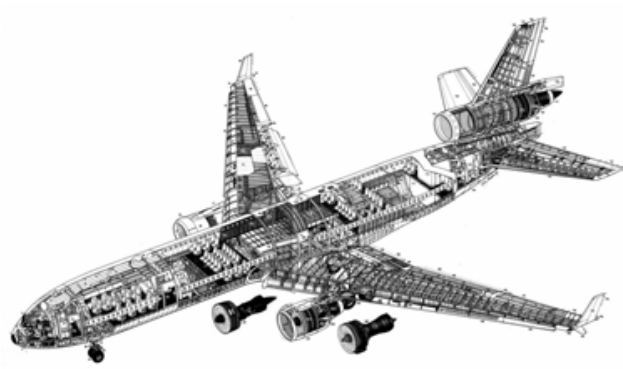

Figure 1: Cutaway illustration of McDonnellDouglas MD-11

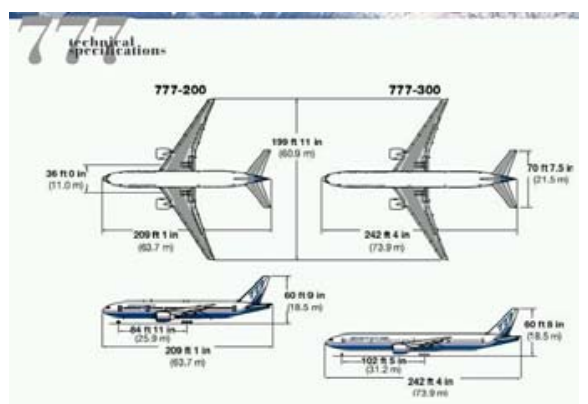

Figure 2: Aircraft 3-view drawing of Boeing $777^{7}$

\section{Scope of Design Study}

For the present study, five different categories of aircraft types were studied. These categories were (with approximate number of specific aircraft models studied in parentheses):

- Commercial Transport Jets (24)

- Business Jets (17)

- Combat Jet Aircraft (65)

- Single-Engine Propeller Aircraft (11)

- Twin-Engine Propeller Aircraft (26) 
Since the main objective of the optimization process is the design of future aircraft, the selected aircraft models were limited to post-WWII vehicles which are more likely to be relevant in considering modern designs.

While large modern aircraft contain literally millions of parts, this study focused only on a few of the key loadbearing structural elements. The elements studied were:

- Wings

- Fuselages

- Spars - number, arrangement and locations, wingbox taper

- Ribs - number, spacing, and orientation

$\circ \quad$ Frames - number, spacing

○ Bulkheads or "stiff" frames - locations

$\circ$ Longerons - number and spacing

\section{Results}

The following section presents the results of the design study for only a select combination of aircraft categories and structural elements in order to keep the length reasonable. It is important to point out that, since these data were obtained mostly through painstaking measurements of cutaway illustrations, they are approximate in nature. The trends shown are meant only to be estimates of industry standards. Actual design guidelines are proprietary to each manufacturer. The intent here was not to "reverse engineer" these designs, but to understand the patterns across several aircraft designs.

\section{A. Commercial Transport Jets}

In order to discern company-wide trends or philosophies, the commercial jets studied were limited to the three main manufacturers in this category: Boeing (707, 727, 737-300, 737-800 747, 757, 767, 777), Airbus (A300, A310, A319, A320, A330, A340-300, A380), and the former McDonnell Douglas DC-jet series (DC-8, MD-80, DC-10, MD-11). Note: The cutaway used for the Airbus A380 appeared to be an artist's conception so may not be accurate.

1. Wing Design

The commercial transports generally had two main wing spars, though some models contain a third spar in the portion of the wing closest to the fuselage. This feature was more common in the Airbus jets. All of these vehicles contained a large number of ribs spaced fairly evenly along the wingspan. A typical transport wing structure is shown in Fig. 3.

The locations of the main wingbox spars for Boeing, Airbus, and DC-jet transports are shown in Fig's. 4, 5, and 6, respectively. Since the sizes of the wings vary between aircraft, the locations are shown as a percentage of the chord (measured from the leading edge) versus percentage of the span

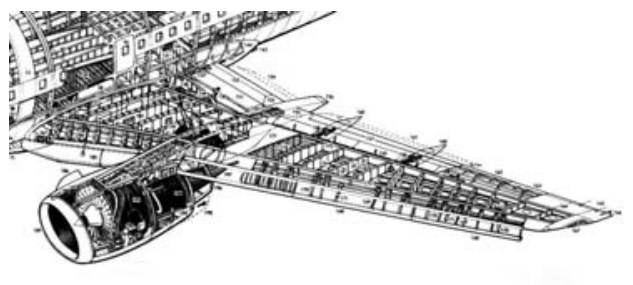

Figure 3: Typical transport wing structure (Boeing 737-300) ${ }^{3}$

(measured from the fuselage). These figures clearly show that the structural layout of commercial transports is extremely stable. Not only is there very little variation from model-to-model within each manufacturer, but there is also very little variation from manufacturer-to-manufacturer.

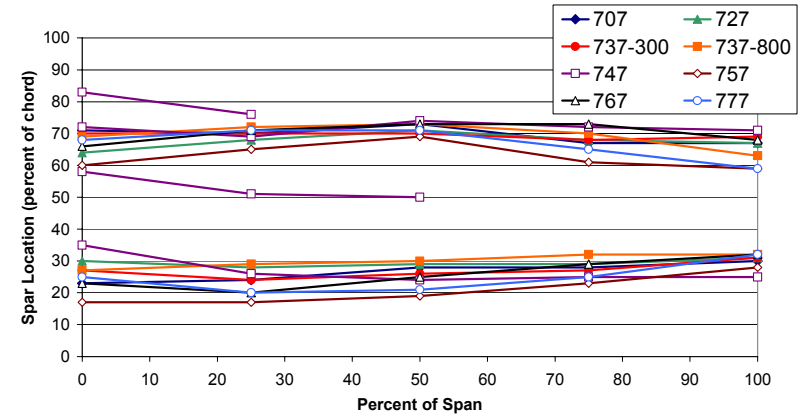

Figure 4: Spar location chart for Boeing 7X7 Series

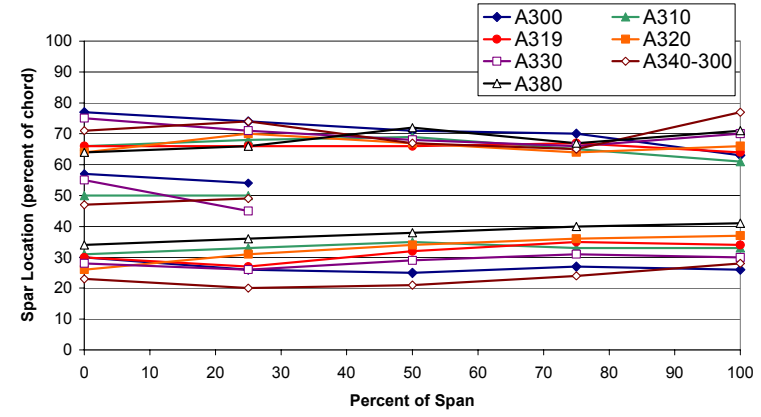

Figure 5: Spar location chart for Airbus Jets 


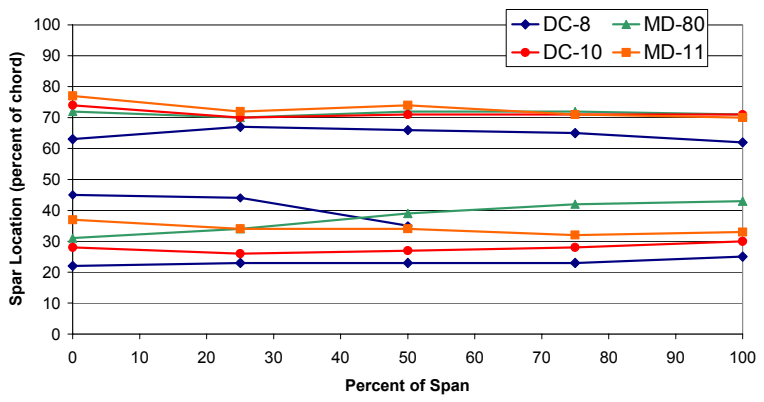

Figure 6: Spar location chart for DC-Series Jets

The wing ribs for transport aircraft are typically uniformly spaced over the majority of the wing span. The average spacing between rib centers for the Boeing, Airbus, and DC-jet transports are shown in Fig's. 7, 8, and 9, respectively. These plots are shown generally in chronological order with older aircraft on the left and newer aircraft on the right. The spacing is shown measured both along the wing sweep direction (i.e. along the wing) and the span direction (i.e. perpendicular to the fuselage axis). These figures also illustrate the "standard" nature of transport design. In virtually every model and manufacturer, the ribs are spaced approximately $2 \mathrm{ft}(0.61 \mathrm{~m})$ apart. The only notable exception is the DC-8-71 which has ribs spaced closer to $3 \mathrm{ft}(0.91 \mathrm{~m})$ apart. (See previous note regarding the Airbus A380). The uniformity of rib spacing for transport jets is most likely driven by maintenance access requirements.

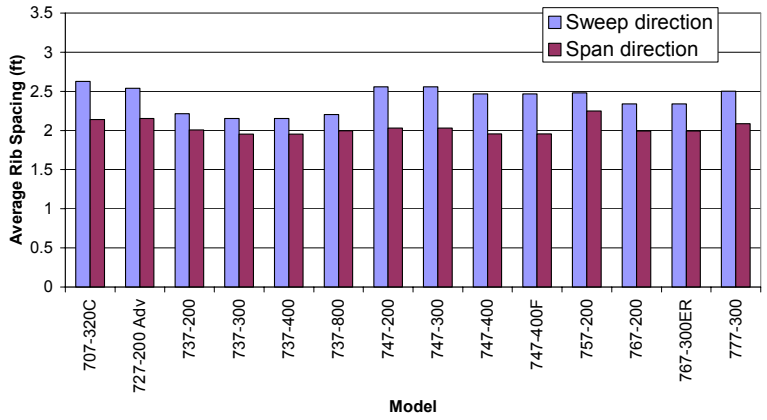

Figure 7: Average rib spacing for Boeing 7X7 series

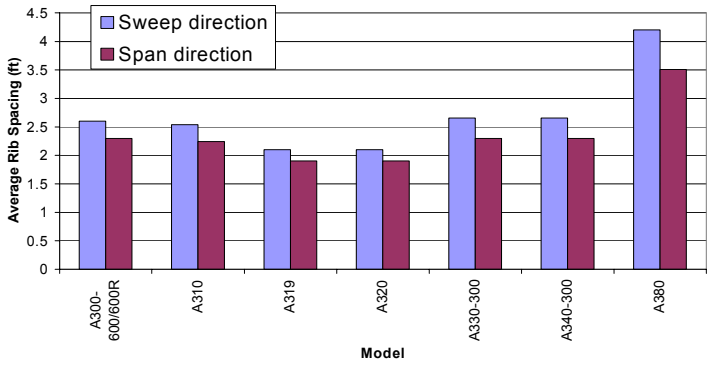

Figure 8: Average rib spacing for Airbus jets

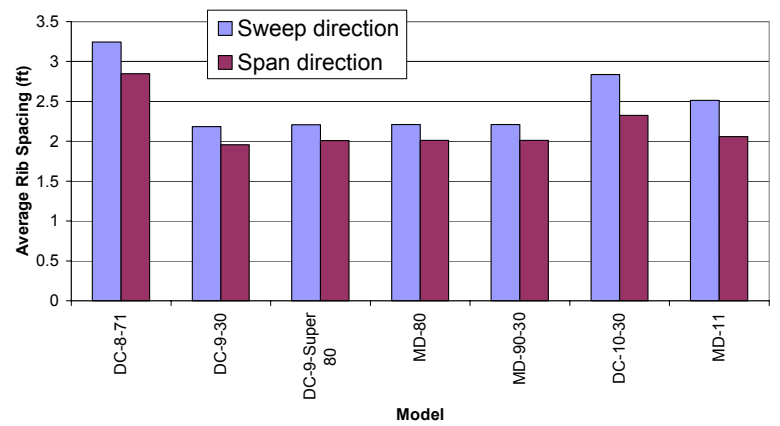

Figure 9: Average rib spacing for DC-series jets 


\section{Fuselage Design}

The main body of transport fuselages is fairly uniform with evenly spaced frames and longerons. "Stiff" frames or bulkheads are used at ends of the pressure vessel and at key attachment points (wings, empennage, engines, doors, etc.). Frames tend to be more closely spaced near the tapered nose and rear of the fuselage where the spacing is more difficult to define. A typical transport fuselage structure is shown in Fig. 10.

The spacing between frames is shown as a function of percent of fuselage length for the Boeing transports in Fig. 11. The frame spacing in the main cabin for the

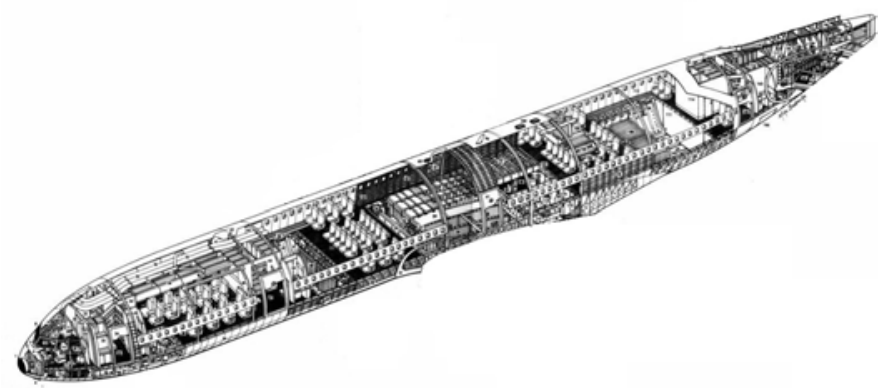

Figure 10: Typical transport fuselage structure (MD-11) ${ }^{5}$ full range of models is fairly constant at $20 \pm 2$ inches. Similar results were found for frame spacing on the Airbus and DC-jets (with the exception of the MD90-30 which has an average frame spacing in the main cabin of approximately 14 inches). An alternative illustration of frame spacing is shown for the Boeing transports in Fig. 12, with older aircraft at the top of the chart progressing to newer aircraft at the bottom.. Here the frames are illustrated graphically along an absolute length scale that permits an easy comparison of the layouts and further illustrates the uniformity of the designs over the range of models and eras.

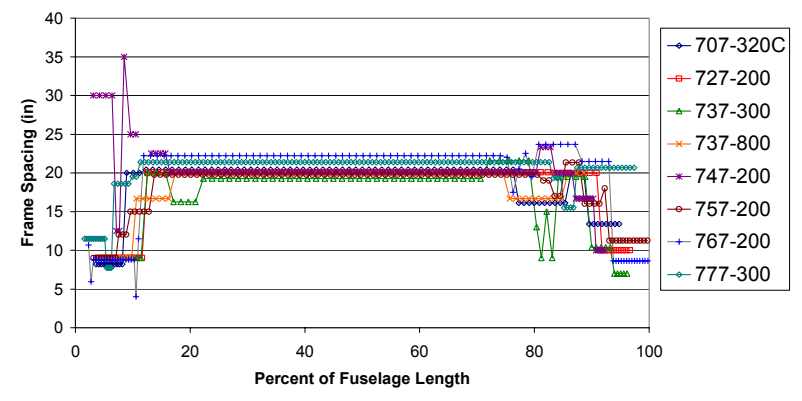

Figure 11: Frame spacing for Boeing $7 \mathrm{X} 7$ series

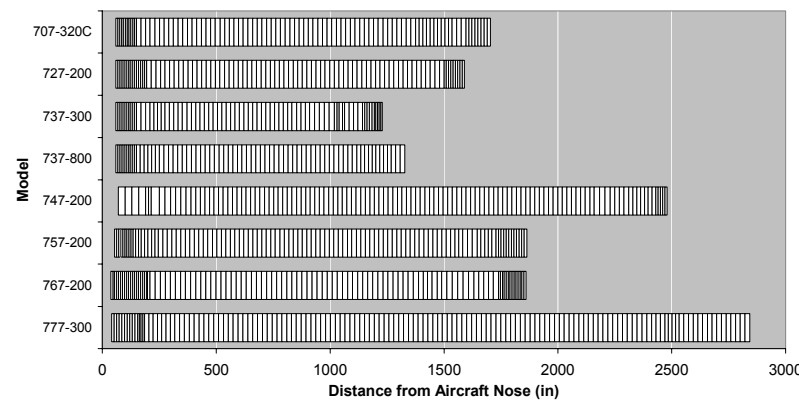

Figure 12: Fuselage layouts for Boeing $7 \times 7$ series

\section{B. Combat Jet Aircraft}

The combat aircraft category was selected to present in this paper due to the fact that the analysis here was qualitatively different than that performed on the aircraft in the other four categories. The wide variation in designs made the plots similar to those presented for the commercial transport jets (i.e. spar location versus span, average rib spacing, frame spacing versus fuselage length) impractical for visualizing design trends. This variation required a less quantitative, though still illuminating, approach.

A total of sixty-five (65) different combat jet aircraft were analyzed for the current study. These included aircraft from the United States, Soviet Union (Russia), Great Britain, France, China, Japan, and Sweden.

1. Wing Design

Wing structure varied widely from aircraft to aircraft in the combat aircraft category. The wide range of missions and capabilities embodied by this group is likely to be a big factor in this observation. While most commercial transport, business, and private aircraft were found to have a maximum of three to four spars, the high maneuver loads seen by some combat aircraft resulted in designs which have at least three spars and typically as many as ten or more. In addition, the wing structure in combat aircraft is often more integrated with the fuselage structure. This can be easily seen in Fig. 13 which shows a typical combat aircraft wing structure.

One particularly illustrative view of wing design practice for combat jets is to compare the number of wing spars and number of rib divisions for different aircraft. This comparison is shown in Fig. 14 for all sixty-five aircraft studied. With a few exceptions, these designs seem to fall into two different categories. One category involves a small number of spars (less than five) and many ribs, much like the transport aircraft. Most of the Russian fighter 
aircraft and older U.S. fighters fall into this category. However, a second category involves wings with have only a few spanwise ribs but a very large number of spars, many with ten or more. This trait is more indicative of modern U.S. fighters (post 1960's aircraft). This differing structural design philosophy is clearly illustrated in Fig. 15 which shows the difference between the wing designs of the Russian Mikoyan-Gurevich MiG-31 Foxhound aircraft and the Lockheed Martin F-22A Raptor. The MiG-31 has only three spars at the wing root, tapering to two at the tip, and eighteen rib divisions. The F-22A is almost the exact opposite, containing only four rib divisions and eighteen spars at the wing root. The number of spars tapers off towards the root, but only due to the wing taper itself.

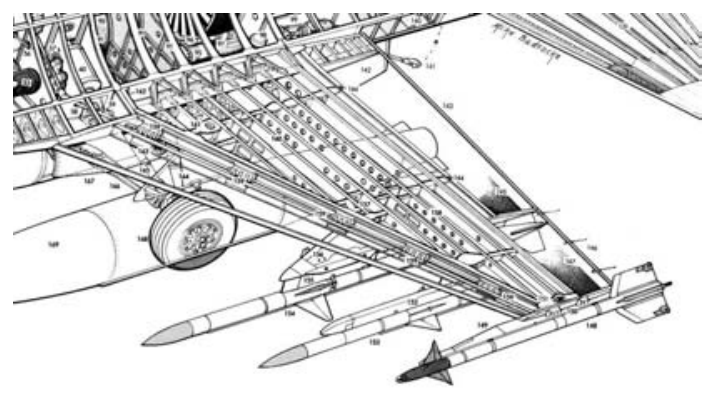

Figure 13: Typical combat aircraft wing structure (Lockheed Martin F-16)

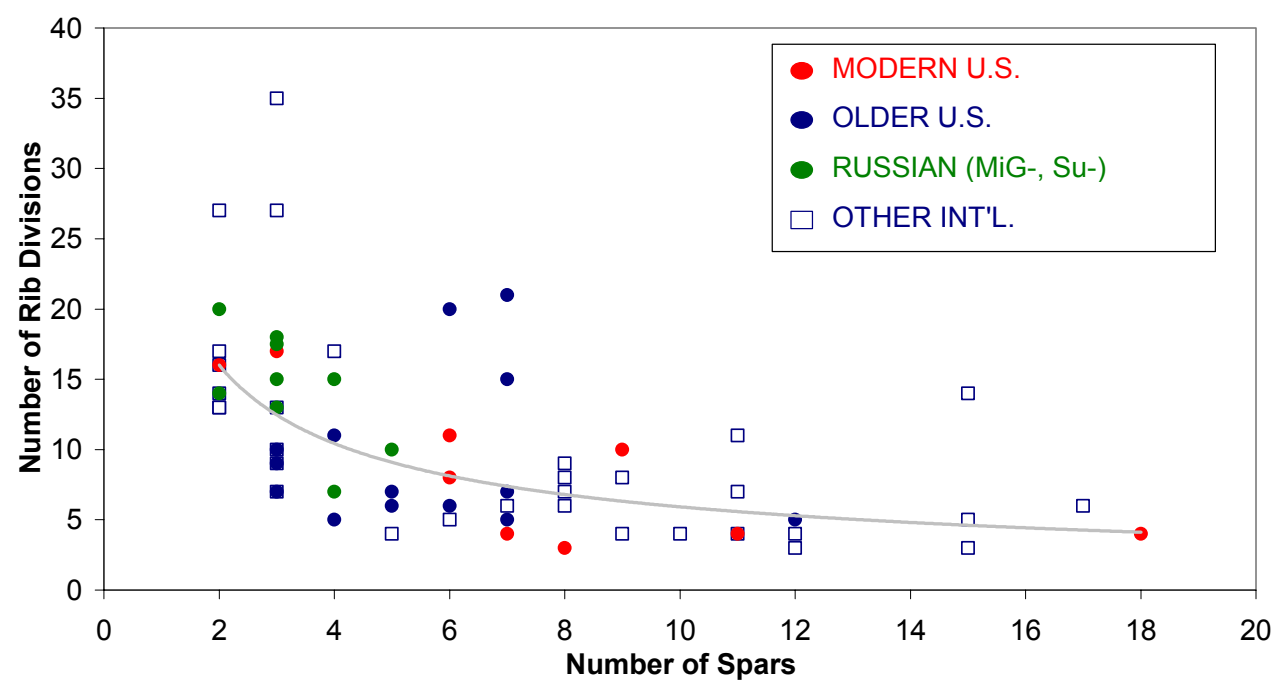

Figure 14: Number of ribs vs number of spars in 65 different combat iet aircraft

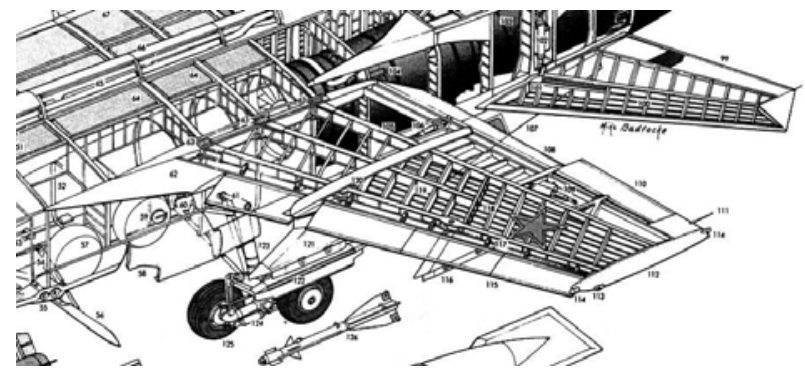

a) Mikoyan-Gurevich MiG-31 Foxhound wing ${ }^{8}$

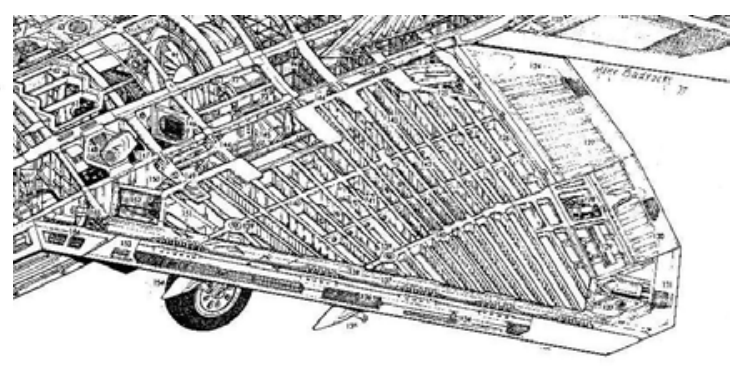

b) Lockheed Martin F-22A Raptor wing ${ }^{4}$

Figure 15: Comparison of Russian-style wing design (few spars, many ribs) with modern U.S.-style wing design (many spars, few ribs)

\section{Fuselage Design}

Combat aircraft fuselage design also varies much more widely than in commercial transports. The basic structure still consists of frames (albeit non-circular ones) and longitudinal support. A typical combat aircraft fuselage is shown in Fig. 16. 
One interesting observation in modern combat aircraft fuselage design is found in the Lockheed Martin F-35 Joint Strike Fighter. The integrated nature of the fuselage and wing result in the inner wing ribs looking (and probably functioning) more like longitudinal fuselage spars. The highly maneuverable nature of aircraft like this one likely increase bending loads on the fuselage itself, necessitating an improved longitudinal capability. This structure is shown in Fig. 17.

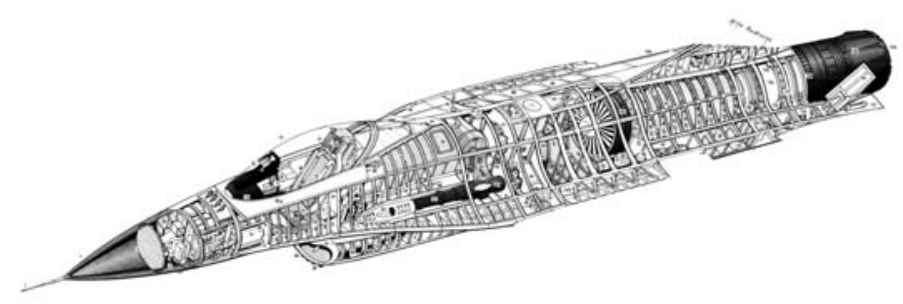

Figure 16: Typical combat jet aircraft fuselage structure (Lockheed Martin F-16) ${ }^{4}$

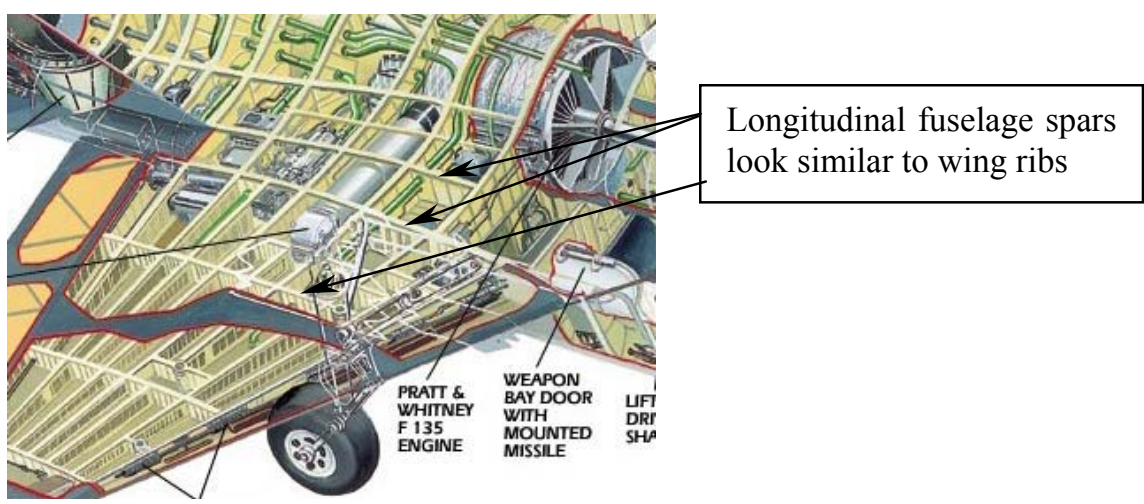

Figure 17: Illustration of longitudinal "fuselage spars" in F-35 JSF wing9

A fuselage layout plot for a number of U.S. combat jets is shown in Fig. 18. The older aircraft shown at the top of this plot exhibit a more uniform layout of fuselage frames, while the newer aircraft near the bottom indicate a more tailored fuselage design.

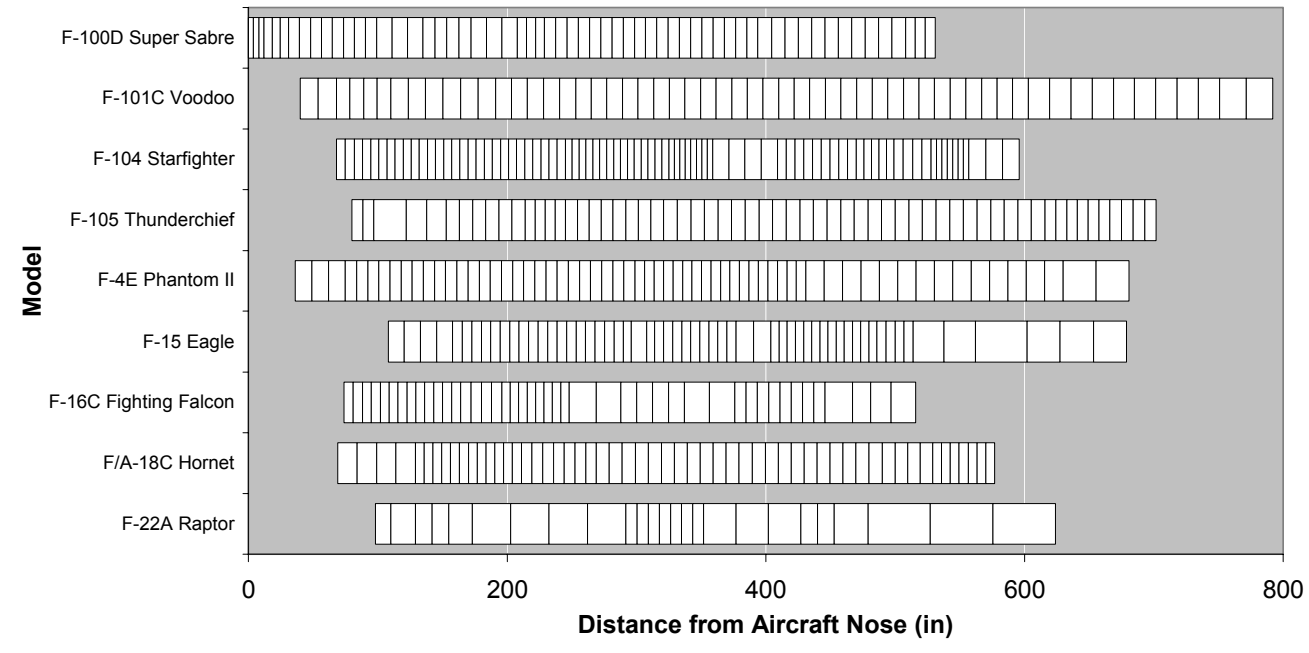

Figure 18: Fuselage layouts for selected U.S. combat jets 


\section{Conclusions}

In this study, a number of post-WWII aircraft from five different categories were analyzed to determine structural design practices and trends. Some of the results for the commercial jet transport and combat jet aircraft were presented and discussed in this paper. The design of commercial transport aircraft was found to be very consistent over a range of eras and manufacturers. Much more variability was found for combat jet aircraft, though some trends were also evident, particularly related to Russian versus modern U.S. designs. The full results of this design trend study will be presented in a future publication.

\section{Acknowledgments}

This study was supported by the NASA Langley Research Center's Multidisciplinary Optimization Branch and was completed under the auspices of the NASA/ASEE Summer Faculty Fellowship Program.

\section{References}

${ }^{1}$ Air Enthusiast magazine, various issues 1971-1973.

${ }^{2}$ Air International magazine, various issues 1974-2003.

${ }^{3}$ Badrocke, M. and Gunston, W., Boeing Aircraft Cutaways: The History of Boeing Aircraft Company, Osprey Publishing Ltd. through Barnes \& Noble Books, 2001.

${ }^{4}$ Badrocke, M. and Gunston, W., Lockheed Aircraft Cutaways: The History of Lockheed Martin, Osprey Publishing Ltd., through Barnes \& Noble Books, 2001.

${ }^{5}$ Badrocke, M. and Gunston, W., The Illustrated History of McDonnell Douglas Aircraft: From Cloudster to Boeing, Osprey Publishing Ltd., 1999.

${ }^{6}$ Gunston, W., The Illustrated Encyclopedia of the World's Modern Military Aircraft, Salamander Books, Ltd., 1977.

${ }^{7}$ Boeing 777 Technical Specifications, General Exterior Arrangements 777-200/-300 [online specifications], URL: http://www.boeing.com/commercial/777family/777technical.html [cited 15 March 2004].

${ }^{8}$ Braybrook, R., "Foxhound: Son of Foxbat," Air International, Vol. 41, No. 3, Sept. 1991, pp. 121-130.

${ }^{9}$ Wilson, J., "Flexible Flier: America’s F-35 Joint Strike Fighter Plane,” Popular Mechanics, May 2002. 